MS36-P15

\section{Synthesis, structural and characterization of three barium aromatic coordination polymers displaying a hydrogen-bonded layer structures}

Balegroune Fadéla ${ }^{1}$, Assia Djeghri ${ }^{1}$, Aouaouche Benkanoun ${ }^{1}$, Slimane Dahaoui

1. Laboratoire CRI-THER, Faculté de Chimie, USTHB, lger, Algeria

2. CRM2, UMR 7036 CNRS, Université de Lorraine BP70239-

54506, Vandœuvre-lès-Nancy, France

email: fbalegroune@yahoo.fr

Coordination polymer materials have been demonstrated to have excellent properties and potential applications such as catalysis, magnetic, optical materials, gas adsorption, antibacterial agents, antitumor drugs, and so on [1-2].

Our research interest has been focused on a systematic study of coordination polymers based $s$-block alkaline-earth metal ions and organic diacids [3]. In this paper, we reported the synthesis and characterization of three Ba coordination polymers from1,2-benzene--dicarboxylic acid $\left[\mathrm{Ba}\left(\mathrm{H}_{2} \mathrm{O}\right)\left(\mathrm{OOC}-\mathrm{C}_{6} \mathrm{H}_{4}-\mathrm{COOH}\right)_{2}\right], \quad$ 2,2'-biphenyldicarboxylic acid $\left[\mathrm{Ba}\left(\mathrm{OOC}-\left(\mathrm{C}_{6} \mathrm{H}_{4}\right)_{2}-\mathrm{COO}\right)\left(\mathrm{H}_{2} \mathrm{O}\right)_{4}\right] \quad 0.25 \mathrm{H}_{2} \mathrm{O}$ and 1,4-butanedicarboxylic acid (adipic acid) $\left[\mathrm{Ba}\left(\mathrm{OO}-\left(\mathrm{CH}_{2}\right)_{4}^{-}\right.\right.$ $\mathrm{COOH}]$. The three compounds crystallise in space groups $\mathrm{P} 2_{1} / \mathrm{c}$ Pcan and $\mathrm{P}-4 \mathrm{~b} 2$ respectively.

The structure of the first complex is built up from polymeric aquabis(hydrogeno-o-phthalate)barium(II) units. Each barium(II) binds to ten O-donors atoms, eight of which belong to six symmetry-related [HBDC] ligands and the remaining two to two water molecules. Thus, the coordination geometry around the $\mathrm{Ba}(\mathrm{II})$ atom can be best described as a distorted bicapped square antiprism. In such a way, the complex units are assembled into a two-dimensional infinite layer structure parallel to the (001) plane. The inorganic barium-oxygen layers are generated from $\mathrm{Ba}_{2} \mathrm{O}_{20}$ units which share faces and edges with neighbours to form chains along the [010] and [100] directions, respectively.

For complex $\left[\mathrm{Ba}\left(\mathrm{OOC}-\left(\mathrm{C}_{6} \mathrm{H}_{4}\right)_{2}-\mathrm{COO}\right)\left(\mathrm{H}_{2} \mathrm{O}\right)_{4}\right] 0.25 \mathrm{H}_{2} \mathrm{O}$, the $\mathrm{Ba}$ (II) ions are ten-coordinated with three carboxylate oxygen atoms and with seven oxygen water molecules. Therefore, the coordination geometry around $\mathrm{Ba}$ (II) ions can be described as distorted bicapped dodecahedra. Its coordination architecture is built up from two-dimensional inorganic sub-networks made from face-sharing ten-coordinated $\mathrm{Ba}$ (II) polyhedra connected by the 2,2'diphenate linkers. Strong hydrogen bonds involving all the coordinated water molecules and the $\mathrm{O}$ atoms of the carboxylate groups lead to the formation of a three-dimensional network.

In the last complex, the asymmetric unit consists of one $\mathrm{Ba}(\mathrm{II})$ cation lying on -4 axis and one half dicarboxylate ligand. The barium is eight-coordinated by eight oxygen atoms belonging to eight equivalent dicarboxylato ligands. The coordination geometry around the $\mathrm{Ba}$ (II) can be best described as a distorted bicapped trigonal prism. The adipate ligands are tetradentate with syn/anti conformation. The structure is built up from chains of isolated polyhedra $\mathrm{BaO}_{8}$ running parallel to [100] axis which are further connected through bridging dicarboxylate anions and separated by an infinite array of alkyl chains into 3D structure.
References:

[1] Tranchemontagne, D. J., Mendoza-Cortés, J. L., O'Keeffe, M. \& Yaghi, O. M. (2009). Chem. Soc. Rev., 38, 1257-1283.

[2] Yan, Y., Yang, S.H., Blake, A. J. \& Schröder M. (2014). Acc.

Chem. Res., 47, 296-307.

[3] Djehni, S., Balegroune, F., Guehria-Laidoudi, A., Dahaoui, S. \& Lecomte, C. (2007). Acta Cryst., C63, m91-m93.

Keywords: Barium, Structure, PCs 